Archives de sciences sociales des religions

110 | avril-juin 2000

Varia

\title{
ALLIEVI (Stefano), I nuovi musulmani. I convertiti all'islam
}

Rome, Edizioni Lavoro, 1999, 296 p. (bibliogr., glossaire) (coll. « Islam. Popoli e culture »)

\section{Giovanni Semi}

\section{CpenEdition}

\section{Journals}

Édition électronique

URL : http://journals.openedition.org/assr/20501

DOI : 10.4000/assr.20501

ISSN : $1777-5825$

Éditeur

Éditions de l'EHESS

\section{Édition imprimée}

Date de publication : 1 juillet 2000

Pagination : $54-55$

ISBN : 2-222-96691-4

ISSN : 0335-5985

\section{Référence électronique}

Giovanni Semi, «ALLIEVI (Stefano), I nuovi musulmani. I convertiti all'islam », Archives de sciences sociales des religions [En ligne], 110 | avril-juin 2000, document 110-2, mis en ligne le 19 août 2009, consulté le 21 septembre 2020. URL : http://journals.openedition.org/assr/20501 ; DOI : https:// doi.org/10.4000/assr.20501

Ce document a été généré automatiquement le 21 septembre 2020

(c) Archives de sciences sociales des religions 


\title{
ALLIEVI (Stefano), I nuovi musulmani. I convertiti all'islam
}

\author{
Rome, Edizioni Lavoro, 1999, 296 p. (bibliogr., glossaire) (coll. « Islam.
} Popoli e culture »)

Giovanni Semi

\section{RÉFÉRENCE}

ALLIEVI (Stefano), I nuovi musulmani. I convertiti all'islam, Rome, Edizioni Lavoro, 1999, 296 p. (bibliogr., glossaire) (coll. « Islam. Popoli e culture »)

1 Après avoir traité la question de la présence islamique en Italie, (notamment dans «Il ritor no dell'Islam ", Edizioni Lavoro, 1993, avec F. Dassetto), S.A. nous offre aujourd'hui un regard très approfondi sur ceux qui, bien que non immigrés, sont devenus musulmans : les convertis. Réélaboration de sa thèse de Doctorat en Sociologie, dont une version est déjà parue en français (Les convertis à l'Islam. Les nouveaux musulmans d'Europe, L'Harmattan, 1998), cet ouvrage fournit un très riche regard à la fois descriptif et analytique, sur le phénomène des conversions à l'islam en Europe aujourd'hui.

2 Les chiffres que l'auteur avance signalent un phénomène plutôt limité, même s'ils sont "alignés sur ceux d'autres pays, et en même temps proportionnels à la présence islamique en Italie ». Il s'agirait d'environ 300 à 400 conversions par an.

3 Au-delà des chiffres, le travail de l'A. s'avère plus révélateur d'un point de vue interprétatif, lorsqu'il saisit les motivations de la conversion. Il développe une typologie distinguant les conversions relationnelles et les conversions rationnelles. Les premières sont surtout liées à des chances extérieures qui ont guidé, sinon directement déterminé, le choix des convertis, tandis que les autres relèvent plutôt de l'aboutissement d'une recherche intérieure plus individuelle. De ce point de vue, la «conversion instrumentale», comme celle opérée par un homme qui désire épouser une femme musulmane, aussi bien que la conversion pour des raisons professionnelles, font partie de la modalité relationnelle. En revanche, les intellectuels à la recherche de 
sens comme Massignon ou Guénon, ou encore les militants de droite ou de gauche, relèvent de la catégorie rationnelle. Alors que chez les militants de gauche, ce sont les sentiments égalitaires et tiers-mondistes qui priment, ainsi que l'esprit du vécu militant et minoritaire (qu'ils transposent dans leur «militantisme » musulman), chez les militants de droite l'esprit "autoritaire» et «dogmatique» ainsi qu'un certain antisémitisme, en quelque sorte réinscrits dans un cadre islamique, prévalent. La conversion leur permet alors de renégocier leur rôle politique et de leadership.

4 L'A. propose une analyse perspicace des modifications qui suivent la conversion. Il les regarde sous l'angle des pratiques islamiques qui découlent des cinq piliers de l'islam, de la dichotomie haramlhalal et des rites de passage - comme les changements de nom ou la circoncision (masculine). Les chapitres IV et $\mathrm{V}$ sont riches en données et en détails sur la vie quotidienne de ces «euro-musulmans » qui participent à la naissance d'une nouvelle culture par leur rôle actif dans les activités de production et de diffusion des textes sur l'islam (ou des traductions du Coran). Il faut remarquer ici que leurs efforts d'interprétation et de création ne semblent pas se nourrir uniquement de la présence des immigrés musulmans, avec lesquels ils entretiennent des relations souvent conflictuelles, dues à un sentiment d'infériorité ou de supériorité. Il leur est en effet souvent difficile d'être mieux préparés théologique ment que les dépositaires de la langue sacrée et du complexe système symbolique arabo- islamique. Si, dans un cas, c'est la fréquentation des immigrés arabophones et musulmans qui a mené vers la conversion, dans un autre, certains éléments marquant le sens commun (ou, si on préfère, le discours sur l'immigration en Italie), comme par exemple l'idée d'une certaine "misère culturelle radicale et irrémédiable » des immigrés, semblent altérer les rapports entre islam d'origine et islam italien.

Très justement, l'A. ne cède pas à la tentation de fournir des prédictions sur les événements futurs, mais il laisse comprendre que le rôle des convertis sera de servir de trait d'union entre deux mondes, celui de l'islam et celui de l'occident. Or, cette conclusion nous inspire la réflexion suivante : l'A. aurait peut-être pu mettre davantage en évidence le caractère pluriel de l'Europe pour mieux contrebalancer le poids donné à la vision plurielle de l'islam. Pluralisme qui n'est pas seulement une différenciation géopolitique, mais surtout une façon plurielle de gérer le rapport au religieux. 